\title{
Simple Experiments with Portulaca Oleracea Cv. for High School Students to Study Phytoremediation
}

\author{
Miyasaka H*, Kondo M, Taniguchi A, Iwai R, Hayashi S and Yamamoto S \\ Sojo University, Faculty of biotechnology and Life Science, Department of Applied Life Science, \\ Japan
}

*Corresponding author: Hitoshi Miyasaka, Sojo University, Faculty of biotechnology and Life Science, Department of Applied Life Science, 4-22-1 Ikeda, Nishiku Kumamoto, Kumamoto 860-0082, Japan, Tel.: +81-963263830; Email: miyasaka@life.sojo-u.ac.jp

\section{Short Communication \\ Volume 4 Issue 7}

Received Date: November 17, 2020

Published Date: November 24, 2020

DOI: $10.23880 /$ jenr-16000222

\section{Abstract}

Portulaca (Portulaca oleracea $c v$.) is a popular floricultural herbal plant, and has a high ability in phytoremediation of various organic contaminants. The roots of portulaca rapidly excrete the peroxidase enzymes into the hydroculture medium. Taking these advantages of portulaca, the experiments for high school students to study phytoremediation were designed, and evaluated in the class activities by 15 second grade high school students.

Keywords: Portulaca Oleracea cv.; Phytoremediation; Peroxidase; High School; Education

\section{Introduction}

Phytoremediation is an environment friendly technology that uses plants for the treatment of soil and water contaminated by toxic pollutants [1]. Portulaca (Portulaca oleracea cv.) is a popular floricultural herbal plant, being seen everywhere spring through early autumn. Portulaca has a quite high ability in phytoremediation of various endocrine disruptors, such as bisphenol A (BPA), octylphenol, nonylphenol and 4,4'-thiodiphenol (TDP) [2,3], and two possible BPA metabolizing mechanisms, namely the polyphenol oxidase (PPO) mediated hydroxylation and the secretory peroxidase mediated oxidation and polymerization, were also proposed [4-6]. Portulaca is also the first plant that was reported to be able to detoxify microcystin-LR, a cyanobacterial toxin [7]. Portulaca is a crassulacean acid metabolism (CAM) plant native to warm region, grows rapidly, and can easily be propagated via cutting. Although portulaca generally prefers hot and dry conditions, this plant is unexpectedly quite suitable to hydroculture. In this study, taking these advantageous features of portulaca, we devised simple hydroculture experiments for high school class to study phytoremediation, and tested it in practice with high school students.

Since the time for one class period in high school is short (for example usually 50 min in Japan), first we examined if portulaca excretes enough amount of secretory peroxidase enzymes into water in short time (less than 30 min). The plant materials, portulaca ( $P$. oleracea $\mathrm{cv}$.), and three reference plants, salvia (Salvia splendens), lavender (Lavandula angustifolia), and rosemary (Rosmarinus officinalis) were purchased from the local market. For the hydroculture experiments for peroxidase excretion, the plants were removed from the pots and the roots were washed thoroughly with tap water to remove soil, and then the roots were soaked in 20 to $30 \mathrm{ml}$ of water in $100 \mathrm{ml}$ beakers (one plantlet per one beaker). For the colormetric detection of the peroxidase enzymes in the hydroculture medium, $1 \mathrm{ml}$ of $1 \%(81 \mathrm{mM})$ guaiacol and $1 \mathrm{ml}$ of sample solution were mixed, and the reaction was started by adding $100 \mathrm{ml}$ of $0.1 \%(29 \mathrm{mM}) \mathrm{H}_{2} \mathrm{O}_{2}$ solution. The activity of the enzyme was determined using a UV-Visible spectrophotometer (Shimadzu UV-1600, Shimadzu Co., Kyoto, Japan), and the 


\section{Journal of Ecology and Natural Resources}

increase in absorbance at $470 \mathrm{~nm}$ was recorded for 4 to 5 min. Figure $1 \mathrm{a}$ shows the changes in the peroxidase activities in the hydroculture medium of portulaca and other reference plants. The peroxidase enzymes were rapidly excreted by portulaca into the medium while only trace amounts of the peroxidase enzymes were detected in the media of other reference plants. Figure $1 \mathrm{~b}$ shows an example of the changes in the color in peroxidase reaction solution of portulaca. The obvious color change of $\mathrm{H}_{2} \mathrm{O}_{2}$ - guaiacol colormetric reaction was observed within $30 \mathrm{~min}$.
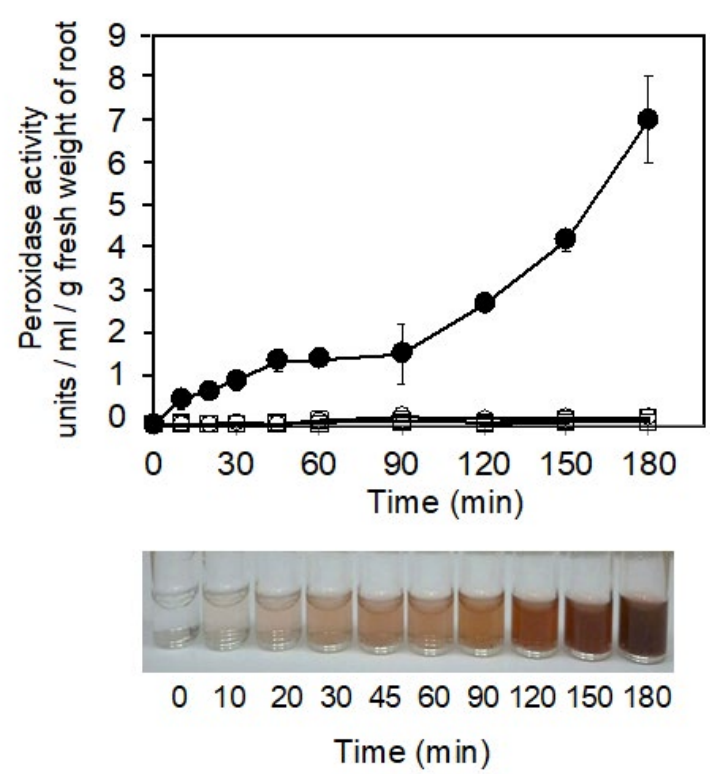

Figure 1: (a) Changes in the peroxidase activities in the hydroculture medium of portulaca and other reference plants (salvia, lavender, and rosemary). The peroxidase activities were assayed by $\mathrm{H}_{2} \mathrm{O}_{2}$ - guaiacol colormetric reaction. The activity of the enzyme was calculated from the extinction coefficient of tetraguaiacol at $470 \mathrm{~nm}\left(26.6 \mathrm{mM}^{-1} \mathrm{~cm}^{-1}\right)$, and expressed as units $\mathrm{ml}^{-1} \mathrm{~g}^{-1}$ (fresh weight of root). Data are means + SD $(\mathrm{n}=3)$. Symbols: closed circle, portulaca; open circle, salvia; open triangle, lavender; open square, rosemary.

(b) Changes in the color in peroxidase reaction solution of portulaca after $0,10,20,30,45,60,90,120,150$, and 180 min of hydroculture.

The rapid peroxidase excretion by portulaca and easy detection method for peroxidase activity indicate that this plant is quite suitable as an educational tool for students to study phytoremediation in high school classes, where the class time is limited and the analytical equipment, such as spectrophotometer, is not generally available. With the help of 15 second grade students ( 3 male and 12 female) of Buntoku Senior High School (Kumamoto, Japan), the lecture and the experiments with portulaca to study phytoremediation were done. The time schedule of the lecture and experiments is shown in Figure 2.

At the beginning of the class, the outline of the experiments was briefly explained to the students, and the hydroculture experiments of portulaca and other 3 reference plants were started. The students were told that only one of the four test plants has a high ability in eliminating organic contaminants in the hydroculture media, and the purpose of the experiments is to find that plants. It takes about 30 min until portulaca excretes enough amount of peroxidase enzyme into the medium for the detection with the naked eyes by $\mathrm{H}_{2} \mathrm{O}_{2}$-guaiacol colormetric reaction, and this waiting period was used for the lecture on general introduction to phytoremediation. Approximately 30 minutes after starting the hydroculture, $1 \mathrm{ml}$ of samples were taken from each medium of portulaca and other 3 reference plants into glass test tubes, and mixed with $1 \mathrm{ml}$ of $1 \%$ guaiacol solution. The peroxidase reaction was started by adding $100 \mathrm{ml}$ of $0.1 \%$ (29 $\mathrm{mM}) \mathrm{H}_{2} \mathrm{O}_{2}$ solution to the samples. The color change (no color to dark orange color) was seen only in the portulaca sample, and the students could easily identify portulaca as the plant with a superior ability of phytoremediation. Since the $\mathrm{Km}$ value for $\mathrm{H}_{2} \mathrm{O}_{2}$ of secretory peroxidase of portulaca is much lower than those of other usual plant peroxidases [4], relatively low concentration of $\mathrm{H}_{2} \mathrm{O}_{2}$ ( $30 \mathrm{mM}$ or less) is suitable for this experiment. In the present study, we used salvia, lavender, and rosemary, as reference plants, which excrete little amount of peroxidase into the medium. The 


\section{Journal of Ecology and Natural Resources}

role of reference plants in the experiments is to intensify the superior ability of portulaca, thus any plants with low ability in peroxidase excretion can be used as the reference plants.

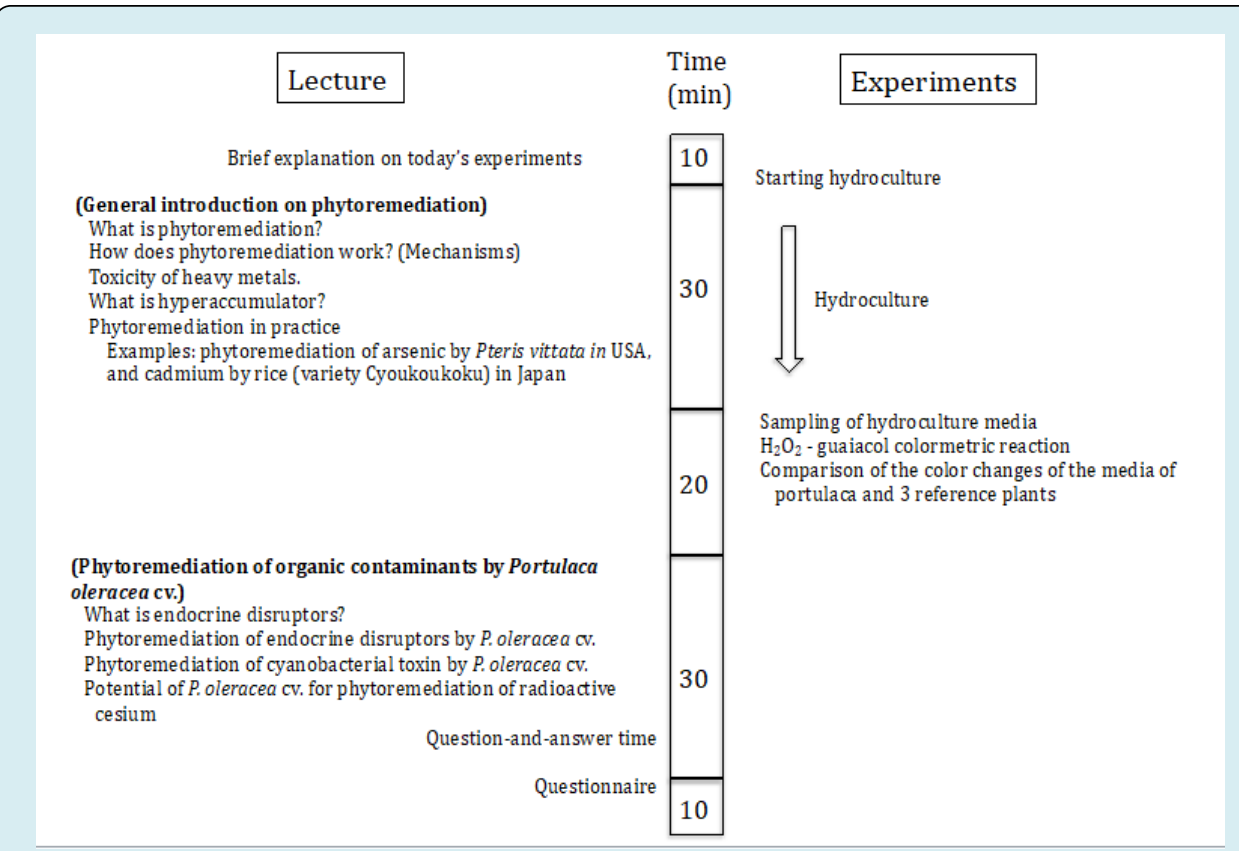

Figure 2: Time schedule of the lecture and experiments.

\begin{tabular}{|c|c|c|c|c|c|c|c|c|c|}
\hline \multicolumn{4}{|c|}{ Not Interesting Enjoyable => Very Interesting Enjoyable } & \multicolumn{4}{c|}{ Not deepen $=>$ Very deepen } \\
\hline 1 & 2 & 3 & 4 & 5 & 1 & 2 & 3 & 4 & 5 \\
\hline 0 & 0 & 0 & 8 & 7 & 0 & 0 & 0 & 6 & 9 \\
\hline
\end{tabular}

${ }^{*}$ The numbers in each column represent the number of students assigning a particular score to each question. All the students answered all questions

Table 1: Result of Likert-type scale survey of students on the interestingness enjoyableness level in experiments and understanding on phytoremidation

After the experiments, the students studied the details of the performance of portulaca in phytoremediation of various toxic chemicals, such as endocrine disruptors [2-6] and cyanobacterial toxins [7] by PowerPoint lecture for about 30 minutes. At the end of the class, a simple Likert-type scale questionnaire survey was done. Students were asked to rank the interestingness/enjoyableness of the experiments on a scale of 1 (not interesting/enjoyable) to 5 (very interesting/ enjoyable), and also their interest and understanding on phytoremediation on a scale of 1 (not deepen) to 5 (very deepen). The result is shown in Table 1 . In general all the students enjoyed the experiments, and their understanding and interests in phytoremediation were much increased. The lecture and experiments with portulaca is, therefore, a quite effective educational tool for high school students to study phytoremediation.

\section{Acknowledgements}

We thank the teachers and students of Buntoku High School for their kind cooperation in our educational research study.

\section{References}

1. Salt DE, Smith RD, Raskin I (1998) Phytoremediation. Annu Rev Plant Phys 49: 643-668.

2. Imai S, Bamba T, Okuhata H, Miyasaka H, Hirata K (2007) Removal of phenolic endocrine disruptors by Portulaca oleracea. J Biosci Bioeng 103(5): 420-426.

3. Matsui T, Nomura Y, Takano M, Imai S, Nakayama H, et al. (2011) Molecular cloning and partial characterization of a peroxidase gene expressed in the roots of Portulaca 


\section{Journal of Ecology and Natural Resources}

oleracea $\mathrm{cv}$., one potentially useful in the remediation of phenolic pollutants. Biosci Biotechnol Biochem 75(5): 882-890.

4. Kaneda H, Matsui T, Tomiyasu R, Kuroda Y, Higashimoto $\mathrm{Y}$, et al. (2012) Isolation of polyphenol oxidase genes from Portulaca oleracea and evaluation of their ability to metabolize endocrine-disrupting chemicals. Plant Biotechnol 29(4): 351-357.

5. Watanabe I, Harada K, Matsui T, Miyasaka H, Okuhata $\mathrm{H}$, et al. (2012) Characterization of bisphenol A metabolites produced by Portulaca oleracea cv. using liquid chromatography coupled with tandem mass spectrometry. Biosci Biotechnol Biochem 76(5): 10151017.

6. Okuhata H, Ninagawa M, Takemoto N, Ji H, Miyasaka H, et al. (2013) Phytoremediation of 4,4'-thiodiphenol (TDP) and other bisphenol derivatives by Portulaca oleracea $\mathrm{cv}$. J Biosci Bioeng 115(1): 55-57.

7. Isobe T, Okuhata H, Miyasaka H, Jeon B, Park H (2014) Detoxification of microcystin-LR in water by Portulaca oleracea cv. J Biosci Bioeng 117(3): 330-332. 